\title{
OS DESAFIOS SOCIOAMBIENTAIS DO CAMPESINATO NO ESPAÇO RURAL DO MUNICÍPIO DE BREJO GRANDE/SERGIPE/BRASIL
}

\author{
Jonas Emanuel da Rocha Antão \\ Mestre em Desenvolvimento e Meio Ambiente PRODEMA/UFS e Bacharelando em Geografia/UFS \\ jonasemanue196@hotmail.com
}

Núbia Dias dos Santos

Professora do Departamento de Geografia, PRODEMA e PROFCIAMB na Universidade Federal de Sergipe nubisantos85@gmail.com

Jonatas Ribeiro Marques Barbosa

Mestrando do Programa de Pós-Graduação em Desenvolvimento e Meio Ambiente/UFS jonatasmarquestb@hotmail.com

\author{
Ajibola Isau Badiru \\ Coorientador do trabalho, Doutor em Ciência Nuclear - IPEN/USP \\ ajibolacanada@gmail.com
}

\section{Resumo}

No nordeste do Brasil ainda persistem conflitos, desigualdade social e regional, envolvendo a reprodução camponesa impactada pelo modelo de desenvolvimento econômico e a atuação dos agentes do capital. Esse trabalho reporta a territorialização do campesinato e os desafios socioambientais ocasionados pela atuação dos empreendimentos capitalistas no munícipio de Brejo Grande/SE. A análise está baseada na revisão bibliográfica, a coleta de dados, pesquisa documental e atividade de campo. A carcinicultura é problemática pelo caráter imperativo do espaço produtivo contra a dinâmica da pesca artesanal. A rentabilidade da atividade pesqueira encontra-se sobre o domínio de agentes externos enquanto a reprodução social camponesa implica em insegurança e danos socioambientais. Sua expansão no território sugere o avanço da desterritorialização dos camponeses pescadores.

Palavras-chave: Camponês. Carcinicultura. Pesca. Rio São Francisco. Território.

\begin{abstract}
In northeastern Brazil, conflicts, social and regional inequality still persist, involving peasant reproduction consolidated by the economic development model and the performance of the agents of capital. This work reports the territorialization of the peasantry and the socioenvironmental challenges produced by the performance of capitalist enterprises in the municipality of Brejo Grande / SE. The analysis is based on literature review, data collection, documentary research and field activity. Shrimp farming is complex across its imperative nature of spatial dynamics against the artisanal fishing with lesser productive environment. The profitability of the fishing activity is subjected to the domain of external agents, while the peasant social reproduction
\end{abstract}


implies insecurity and socio-environmental damage. This territorial expansion suggests serious deterritorialization of the fishermen peasants.

Keywords: Peasant. Shrimp farming. Fishing. São Francisco River. Territory.

\section{Introdução}

Os camponeses são sujeitos que compõem uma classe social, com um modo de vida singular e heterogêneo, sendo híbrida, é uma classe que depende da sua força de trabalho, mas também detém a propriedade da terra. A sua existência é de fundamental importância para a manutenção da sociedade e do próprio sistema capitalista, contraditoriamente, os agentes modeladores do espaço tentam inviabilizar a reprodução social do camponês.

O município de Brejo Grande está localizado no estado de Sergipe, a margem do Rio São Francisco e é banhado pelo Oceano Atlântico. Essa área foi afetada primeiramente pelas mudanças do regime das águas do Rio São Francisco devido à operacionalização da hidrelétrica de Xingó e posteriormente a inserção das atividades da aquicultura que para se instalar necessita retirar a vegetação, afetando a reprodução das espécies nativas que são o sustento dos pescadores e marisqueiras.

Esse trabalho apresenta a análise realizada sobre a territorialização do campesinato frente aos desafios socioambientais, ocasionados pela atuação dos empreendimentos do Estado-Capital no supracitado munícipio. Sendo assim, busca-se analisar a totalidade sócio-espacial ${ }^{1}$ através das atividades pesqueiras a partir das duas modalidades: a pesca empresarial e a artesanal. Com base nos relatos e nas falas dos sujeitos, foi possível entender como o conflito entre camponeses e carcinicultores (agentes do capital) impacta a relação entre os seres humanos entre si e com o meio, afastando o homem do convívio com a totalidade da vida.

O estudo transcorre metodologicamente a partir: 1) o levantamento de fontes bibliográficas sobre os conceitos e o modelo de desenvolvimento colonialista; 2) a coleta de dados nos sites oficiais do Estado, como o IBGE e o Atlas da Macro Fauna, elaborado pela Universidade Federal de Sergipe e publicado em Boletim; 3) e a pesquisa de campo com a observação, rodas de conversas e aplicação de formulários junto aos camponeses das águas ${ }^{2}$ em Brejo Grande. 
O artigo é composto por dois tópicos intitulados: 1) A materialização do modelo de pensamento colonialista desterritorializador no território do município de Brejo Grande/SE; 2) Território municipal de Brejo Grande: Desafios e disputa pela riqueza das águas, mais a introdução, metodologia e as considerações finais.

No primeiro tópico são apresentadas as questões teóricas a respeito do modelo de desenvolvimento cartesiano implantado no mundo, que adentra o espaço-território rural brasileiro e que tem ocasionado uma redução da sociobiodiversidade a partir da implantação de atividades produtivas, que caminham na contramão do respeito ao movimento da vida.

No segundo tópico são apresentadas as caraterísticas sociais do município de Brejo Grande/SE. Segue-se discutindo: 1) A interferência do Estado a partir da construção do projeto hidroelétrico em Sergipe e como esse objeto geográfico externo ao município de Brejo Grande interferiu no território dos pescadores; 2) por meio dos dados oficiais do IBGE é analisado como está a produção empresarial pesqueira no município e como ela afeta a sociobiodiversidade; 3) a partir dos dados do boletim do Atlas da Macro Fauna é possível entender o papel dos pescadores artesanais, com destaque as marisqueiras, e como o trabalho deste coletivo gera riquezas com baixos custos ambientais para o município; 4) antes das considerações finais, é analisado e comparado os ganhos e impacto socioeconômico e ambiental que o grupo dos carcinicultores e camponeses ocasionam no território em estudo.

Nas considerações finais, conclui-se que a inserção dos modelos de desenvolvimento capitalista ocasiona a dependência dos sujeitos sociais para a necessidade de comprar alimentos em outros municípios e ter acesso a um leque maior de políticas públicas para garantir o sustento da família.

O modelo de desenvolvimento do Estado-Capital ocasiona o aumento da dependência dos camponeses em relação ao aparato do Estado. Ocorre também que, os camponeses são induzidos à miserabilidade ou são induzidos a adentrar no ramo da carcinicultura. Entretanto essa modalidade materializa-se dentro de um período de tempo limitado, em vista do esgotamento das condições aquáticas para a manutenção da atividade e da sua produtividade. Diante do exposto, o que vislumbra como cenário futuro para os pescadores artesanais que se tornam carcinicultores é a perda da sua identidade sociocultural e do seu território, no momento em que a carcinicultura tornar- 
se inviável no atual território, obrigando-os a se territorializarem em outros espaços com condições materiais e simbólicas incertas.

\section{A materialização do modelo de pensamento colonialista desterritorializador no território do município de Brejo Grande/SE}

Desde o início do século XVI, com as Grandes Navegações, o mundo passa por transformações apoiadas no avanço da técnica como a bússola, astrolábio, quadrante e as caravelas. Esses instrumentos possibilitaram aos europeus chegarem aos lugares antes desconhecidos por eles, levando o preceito moderno e colonialista a outras localidades do Globo (GALEANO, 2016).

Ao chegar ao lado oposto do Oceano Atlântico, os portugueses, espanhóis, ingleses, franceses depararam-se com um "novo mundo" aos olhos deles, isso também se aplica aos povos que habitavam este solo que posteriormente foi nomeado por América e Brasil. Todavia, esse encontro de dois mundos ocasiona conflitos, contrastes e contradições que a natureza da racionalidade do povo invasor não conseguiu assimilar, provocando genocídios e etnocídios em toda a América Latina (GALEANO, 2016), desterritorializando os povos originários.

Esse modelo de pensamento desterritorializador continua atualmente, mesmo após meio milênio, o modelo de desenvolvimento aportado na técnica e no lucro, continua afetando o modo de vida dos sujeitos campesinos. Essa realidade é visível e materializada através dos danos ocasionados pela construção e operacionalização da hidrelétrica de Xingó em 1994, localizada entre as cidades de Canindé de São Francisco/SE e Piranhas/AL (Chesf, 2016), respectivamente no Alto Sertão Sergipano e Alagoano.

A interferência do Estado é direcionada pelo modelo de desenvolvimento capitalista-colonizador na bacia do Rio São Francisco e tem ocasionado danos ambientais que afetam a totalidade da vida. A primeira interferência no rio, em Sergipe, foi a construção da hidrelétrica de Xingó que ocasionou a alteração do ritmo das águas, posteriormente, ocorreu por parte do Estado, o estímulo à construção dos tanques de carcinicultura na área da bacia, ambos os projetos afetaram o território de vida dos camponeses da água no município de Brejo Grande/SE (mapa 01). 
Mapa 01: Territórios e municípios inseridos na região hidrográfica do Rio São Francisco, Sergipe, Brasil,

2019.

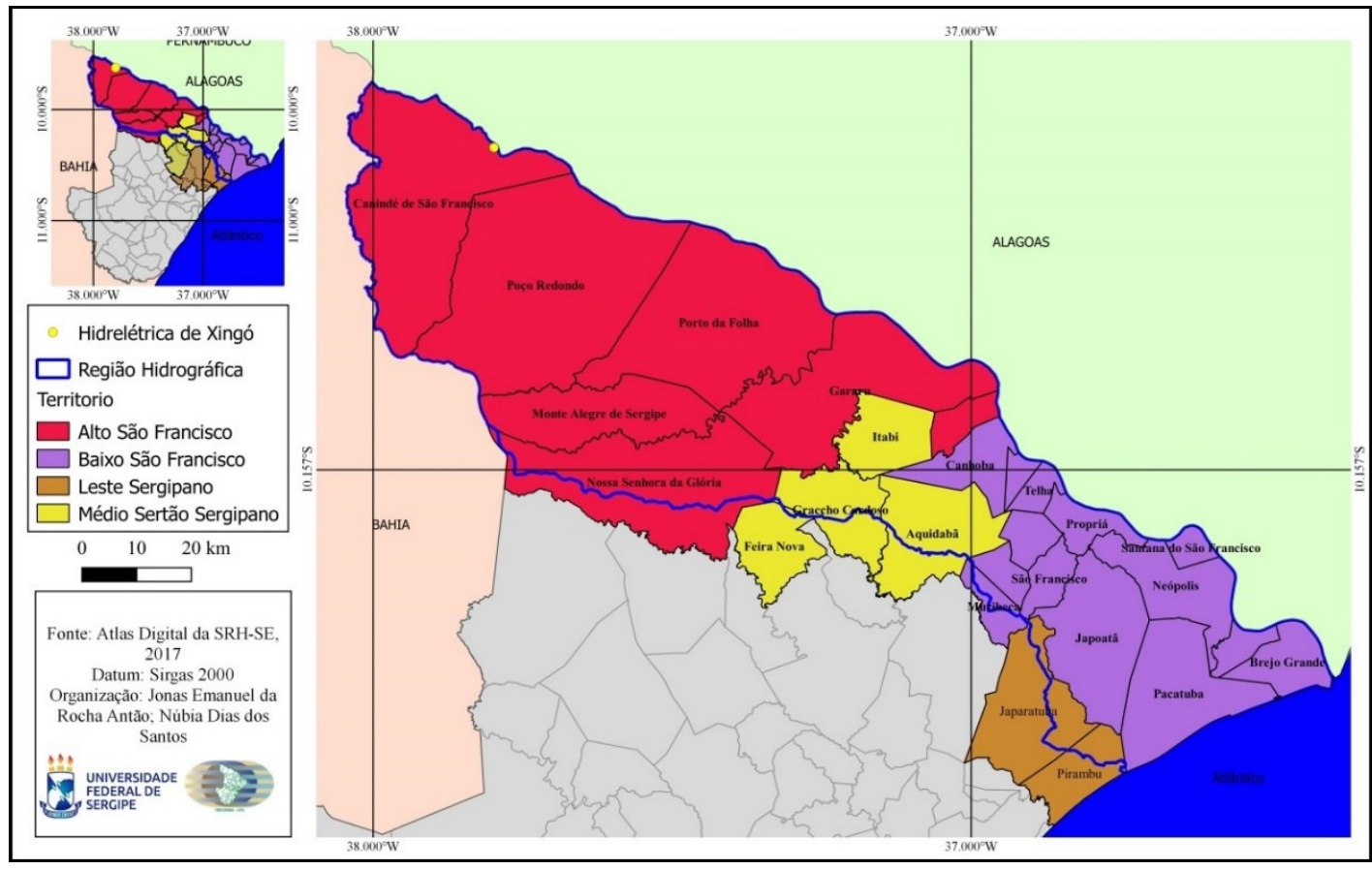

Fonte: Atlas Digital da SRH-SE, 2017.

Organização: Jonas Emanuel da Rocha Antão; Núbia Dias dos Santos, 2019.

O projeto cartesiano-moderno-colonial idealizado pelos países centrais, como Inglaterra, França, Portugal, Espanha e Holanda, afetou e ainda afeta a organização sócio-espacial brasileira e consequentemente o território sergipano. Essa racionalidade estruturou um modelo que ocasiona conflitos, contrastes e contradições com a vida, pois a importância desse modelo racional é o econômico (SANTOS, 2000; 2002; 2008). Ademais, no seu processo de territorialização esse projeto origina danos ambientais nos locais onde é implantado, sendo que no município de Brejo Grande/SE, a área da pesquisa, essa racionalidade é materializada através da aquicultura (carcinicultura).

A prática da aquicultura (carcinicultura) é pautada sob a égide do pensamento cartesiano, na qual a supervalorização da técnica é direcionada para o serviço do capetalismo $^{3}$ (ACOSTA, 2016; BOFF, 2014; MARQUES, 2016), ocasiona a construção de viveiros para a criação de camarão, aprisionando a vida, passando a reorganizar o espaço e inviabilizando-o, dificultando e limitando algumas atividades, como a coleta de mariscos e a reprodução dos seres vivos, haja vista que, para a construção dos viveiros faz-se necessário a retirada da vegetação nativa (mangue). 
É nítido que a operacionalização dos viveiros ocasiona perda de vidas humanas. Um dos entrevistados relatou que já ocorreu o assassinato de um camponês por capataz que tentou impedir o pescador de transitar pelos muros dos viveiros. Ocorre também o impedimento deles atracarem os seus barcos nos portos historicamente constituídos pelos seus antepassados, haja vista que, os campesinos negros pescadores estão na região há aproximadamente 200 anos.

O modo de produção capitalista provoca a degradação dos meios de sobrevivência da teia da vida, consequentemente reduz a autonomia e amplia a dependência dos sujeitos camponeses (SANTOS, 2012). O modo de vida campesino quilombola pescador segue o ritmo das águas, suas atividades laborais provocam um baixo impacto ambiental, contribuindo para a manutenção dos ecossistemas. A territorialização desses dois modos ocasiona conflitos socioterritoriais no município de Brejo Grande/SE.

\section{Território municipal de Brejo Grande: Desafios e disputa pela riqueza das águas}

O município de Brejo Grande está localizado na margem sergipana do Rio São Francisco, nas proximidades da sua foz, além de ser banhado pelo Oceano Atlântico. Em 2010, conforme o censo demográfico do IBGE, a sua população municipal era de 7.742 habitantes, estimada em 2018 para 8.264 habitantes.

Em Brejo Grande no ano de 2017 somente 6,5\% da população exercia cargos/postos de trabalho com carteira assinada. Desse modo, a economia do município, tem como base econômica as atividades laborais realizadas pelas famílias camponesas das águas, que segundo o CadÚnico, em março de 2019, totalizam aproximadamente 658 famílias que dedicam suas vidas a pesca artesanal. Dos 7.742 habitantes, 34,0\% da população em 2010 encontrava-se na extrema pobreza, sendo que 19,3\% desse contingente estavam na zona rural (BRASIL, 2018).

Antes da operacionalização da Hidrelétrica de Xingó, em 1994, as atividades da pesca e da rizicultura eram preponderantes para a reprodução dos camponeses. Com a operacionalização e redução da vazão das águas, ocorreu a salinização da água do Rio São Francisco, inviabilizando a produção de Arroz (Gráfico 01), como também, a reprodução de algumas espécies nativas. 
Gráfico 01: Quantidade em toneladas da lavoura de arroz em Brejo Grande/SE, 19892018.

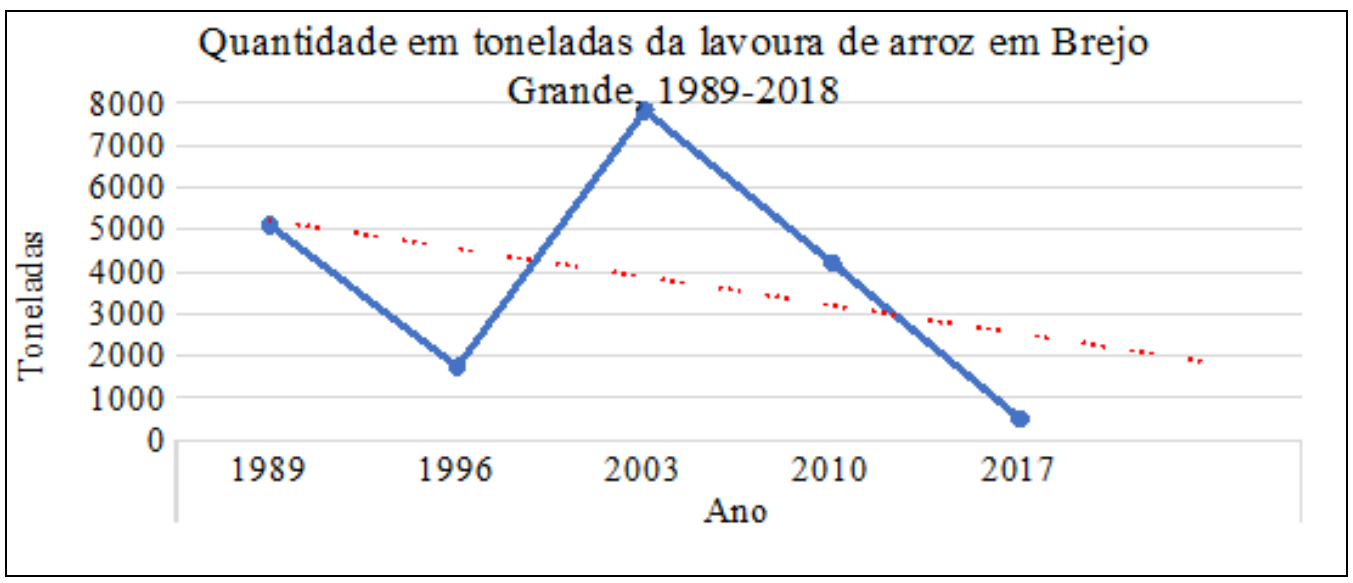

Fonte: IBGE - Produção Agrícola Municipal, 1989-2018.

Organização: Jonas Emanuel da Rocha Antão, 2019.

O gráfico 01 evidencia o recuo na produção da rizicultura em Brejo Grande, mesmo em 2003 ocorrendo uma produção de 7.820 mil toneladas de arroz com casca, a linha de tendência (vermelho) demonstra que de 1989 a 2018, ocorre uma drástica queda na produção. Dessa maneira, a operacionalização da hidrelétrica de Xingó ocasionou mudanças na agricultura do município em tela.

A hidroelétrica é objeto geográfico externo ao município, mas a sua operacionalização afetou a drenagem do canal principal da bacia hidrográfica do Rio São Francisco, o que provocou um movimento de causas e efeitos que originou/origina novas necessidades ao campesinato (quilombola, pescador, marisqueira) que antes não existia nos munícipios do Baixo São Francisco Sergipano.

Os campesinos do Baixo São Francisco Sergipano encontram uma "nova" necessidade de comprar o arroz produzido em outros municípios ou em outros estados, além da redução ou desaparecimento de espécies de peixes, essa situação interfere diretamente na renda dos camponeses pescadores e agricultores e na sua alimentação.

A salinização e o controle da vazão da água do Rio São Francisco ocasionaram a desterritorializacão da rizicultura em muitas áreas do município de Brejo Grande, direcionando os sujeitos a adotarem uma nova atividade no município que foi a aquicultura, principalmente a criação de camarão (carcinicultura), ocorrendo assim a territorialização e espacialização da aquicultura no município. 
Considerando que o município apresenta uma quantidade expressiva de pescadores, essa realidade facilitou o processo de inserção da aquicultura nessa área. Logo, a pesca artesanal e a criação de espécie em viveiros (aquicultura) tornam-se atividades de destaque para a reprodução social do campesinato, ou seja, a reprodução da vida imaterial e material perpassa pela água.

Em busca de entender como essas atividades influenciam a vida e a dinâmica dos camponeses e do município, iremos analisar e comparar a produção oficial/convencional/empresarial e a produção oriunda da pesca artesanal e mariscagem para compreender o papel que cada setor desempenha no tocante ao Produto Interno Bruto Municipal da agricultura, que em 2016 foi de $\mathrm{R} \$ 16.636 .370,00$ (dezesseis milhões, seiscentos e trinta seis mil, trezentos e setenta reais) e para a organização territorial (IBGE, 2016).

A produção pesqueira empresarial é estimulada e incentivada pelo Estado, com o objetivo de tentar minimizar a redução da renda da população, ocasionada pela instalação da hidrelétrica de Xingó. Segundo os dados do Instituto Brasileiro de Geografia e Estatística, foram registradas a criação de seis espécies aquáticas no município de Brejo Grande/SE: A Curimatã/Curimbatá, Tambaqui, Tilápia, Ostras, Vieiras, Mexilhões e o camarão (gráfico 02).

Gráfico 02: Quantidade e tipo de produtos da aquicultura no Município de Brejo Grande em Sergipe/Brasil, 2014-2018.

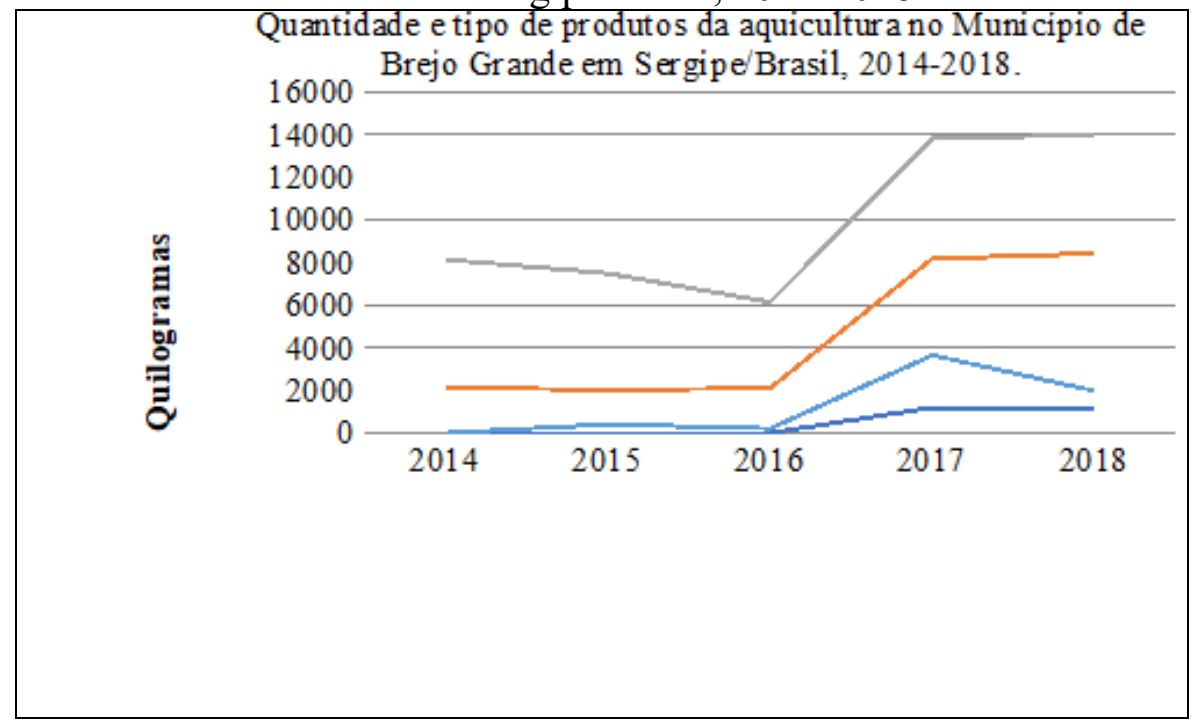

Fonte: IBGE - Pesquisa da Pecuária Municipal, 2018.

Organização: Jonas Emanuel da Rocha Antão, 2019. 
Conforme o Gráfico 02 existe no município de Brejo Grande a produção de Curimatã/Curimbatá, essa espécie é nativa do Rio São Francisco e foi adaptada para criação em cativeiro. A sua produção começou a ser registrada pelo IBGE a partir de 2017 e foi de 1200 quilogramas, e no ano seguinte apresentou queda de 100 quilogramas ficando em 1100 quilogramas.

A produção de Tambaqui, que não é espécie nativa do Rio São Francisco, apresenta oscilação na sua produção durante o tempo, sendo que, o menor registro foi em 2016 com 2.100 quilogramas e a maior em 2018 com 8.430 um crescimento de 250 quilogramas.

O gráfico 02 também apresenta a criação de outra espécie não nativa do rio São Francisco, a Tilápia, assim como o Tambaqui, a Tilápia apresentou a menor produção em 2016 com 6.144 quilogramas e a sua maior produção foi de 13.986 quilogramas em 2018, um crescimento de 156 quilogramas se comparado ao ano anterior.

Brejo Grande também produz Ostras, Vieiras e Mexilhões (moluscos), a sua menor produção foi de 210 quilogramas no ano de 2016. Entre 2016 e 2017 a produção teve um aumento de $1.738 \%$, chegando a produzir 3.350 quilogramas, e em 2018 apresentou uma retração de 54,2\% (Gráfico 02).

O discurso econômico, científico e ideológico afirma que a evolução da técnica permitiria ao camponês uma estabilidade na produção e a garantia de lucros crescentes. Os dados do Gráfico 02 evidenciam que mesmo com a intervenção humana no estuário do Rio São Francisco, não é possível manter uma produção linear, pois a natureza não suporta tal modelo de desenvolvimento.

O IBGE não contabiliza a produção dos pescadores artesanais e das marisqueiras, haja vista que, não é registrado a produção de siri, caranguejos e outros seres vivos coletados no mangue. Isto dificulta a criação de políticas públicas específicas para esse grupo da sociedade, como também, o reconhecimento da profissão das marisqueiras que facilitaria o acesso aos direitos constitucionais previdenciários, uma vez que elas apresentam doenças próprias da profissão, apresentando demandas específicas que deveriam ser consideradas para a construção de um regime de previdência especial.

Destaca-se em Brejo Grande a produção de camarão destinada ao mercado externo, incentivado pelo governo do estado de Sergipe. Os dados do gráfico 03 
revelam que em 2014 a colheita de camarão foi de 495.400 quilogramas, ocorrendo uma redução na quantidade produzida em 458,8\% entre os anos de 2014 e 2016. Entre 2016 e 2018 a produção aumentou para 537.301 quilogramas de camarão.

Gráfico 03: Produção de camarão no Município de Brejo Grande em Sergipe/Brasil, 2014-2018.

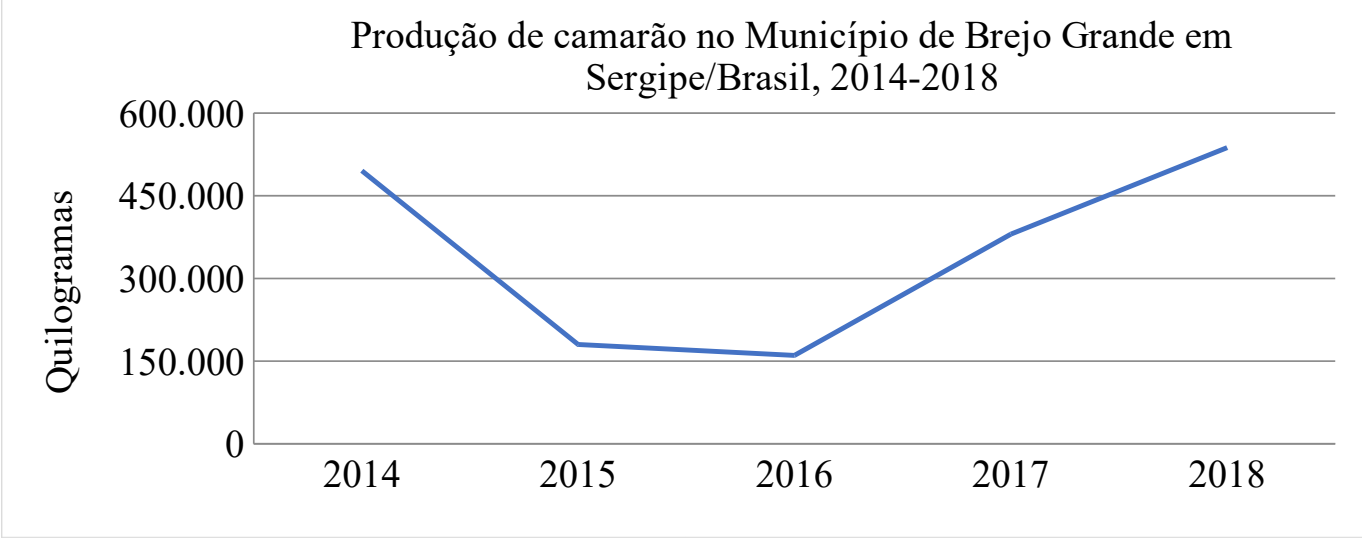

Fonte: IBGE - Pesquisa da Pecuária Municipal, 2018.

Organização: Jonas Emanuel da Rocha Antão, 2019.

Para a criação do camarão, faz-se necessário a retirada da vegetação nativa, ou a sua inserção nas chamadas áreas de apicum, onde não ocorre a presença de vegetação, o que é permitido pela lei $n^{0} 12.651 / 2012$. Todavia, é possível identificar que em Brejo Grande os viveiros são construídos a partir da retirada do mangue, afetando a reprodução das outras espécies nativas, incluindo os seres humanos (Imagem 01).

Imagem 01: Viveiros de camarão no município de Brejo Grande e a vegetação (mangue) desenvolvendo dentro e ao redor do viveiro, 2018.

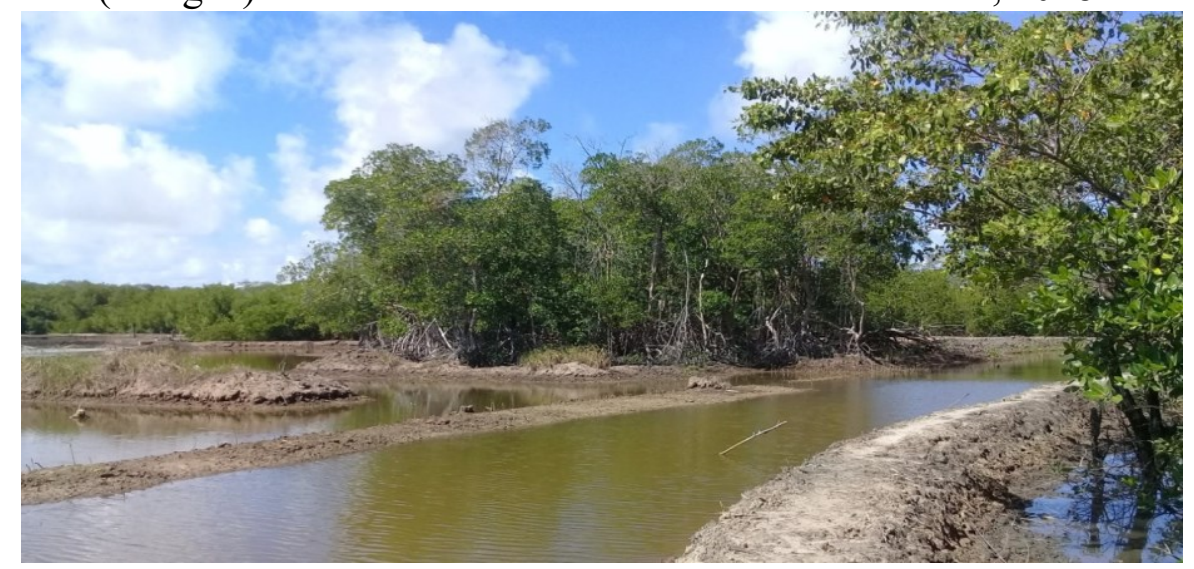

Fonte: Jonas Emanuel da Rocha Antão, 2018. 
Ainda conforme os gráficos 02 e 03, não foram registrados em Brejo Grande a produção de Larvas/pós-larvas de camarão, isto, atrelado a informação de um produtor, as larvas são produzidas em outro município. Essas informações sinalizam para uma maior dependência do campesinato brejo-grandense em razão da necessidade em comprar e transportar as larvas de outros locais, gerando novos custos na cadeia produtiva.

Enquanto os carcinicultores e agentes do estado produzem um território monocultor que reduz a biodiversidade local, os camponeses produzem o território-vida a partir da pesca de diversos animais que vivem no estuário do Rio São Francisco.

Os dados de 2014 demonstravam que Brejo Grande reunia o segundo maior número de pescadores de Sergipe, $15,2 \%$, e era a sétima receita do estado na venda dos produtos oriundos da mariscagem e da pesca artesanal, que contabilizou $\mathrm{R} \$ 2.009 .799,40$ (dois milhões, nove mil, setecentos e noventa e nove reais e quarenta centavos), $4 \%$ da receita do setor dos municípios pesquisados ${ }^{4}$ no estado de Sergipe.

A produção total provinda da pesca artesanal do estuário do Rio São Francisco correspondeu a $\mathrm{R} \$ 2.396 .531,82$ (dois milhões, trezentos e noventa e seis mil, quinhentos e trinta e um reais e oitenta e dois centavos), esse valor corresponde aos dados oficiais registrados pelo Projeto de Monitoramento Participativo do Desembarque Pesqueiros (PMPDP) realizado no âmbito da UFS/PETROBRAS/FAPESE (ARAÚJO et. al, 2016). Equivale também às espécies pescadas e coletadas pelos pescadores e marisqueiras no estuário do Rio São Francisco. Enquanto a produção capitalista se restringe a 7 espécies (Curimatã, Tambaqui, Tilápia, Ostras, Vieiras, mexilhões (moluscos) e camarão), a produção camponesa corresponde a mais de 10 espécies (Caranguejo, Tainha, Pilombeta, Tinhga, Ostra, Curimã, Guaiamum, Robalo, Carapeba, Sururu e outras) (Gráfico 04).

Em termos quantitativos a diferença de espécies, 7 (pesca empresarial) e 10 (Pesca artesanal), aparenta ser insignificante, mas enquanto o ramo empresarial necessita destruir o berçário da vida marinha (mangue) para a reprodução da sua atividade, os camponeses não necessitam agredir o meio ambiente para pescar ou coletar essas espécies. Os seres vivos de origem da pesca artesanal apresentam quantidades e valores diferenciados que contribuem para a comercialização total (Gráfico 04). 
Gráfico 04: Percentual de cada produto da pesca artesanal no valor total da comercialização das espécies proveniente do estuário do baixo Rio São Francisco, 2014.

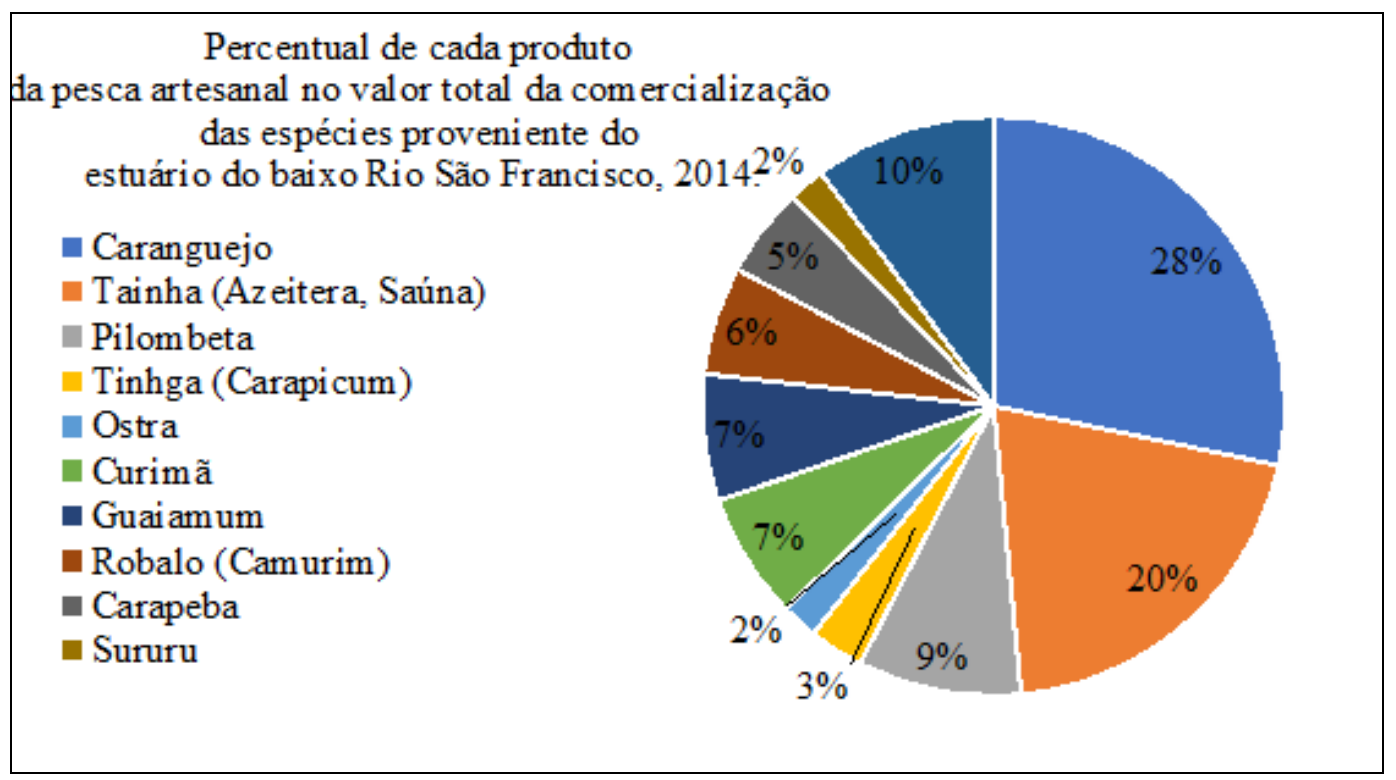

Fonte: Boletim Estatístico da Pesca nos Litorais de Sergipe e Extremo Norte da Bahia, 2014. Organização: Jonas Emanuel da Rocha Antão, 2019.

Dentre as espécies registradas no Gráfico 04, três espécies (Caranguejo, Guaiamum e o Sururu) apontam a participação da mariscagem na geração de renda para o sustento da unidade familiar camponesa, mas também, sinaliza o papel das marisqueiras na constituição do PIB da região.

Conforme o Gráfico 04, o Caranguejo correspondeu a $28 \%$ do montante arrecadado, seguido por Guaiamum (7\%) e o Sururu (6\%), somente essas três espécies compõe $41 \%$ do PIB que é oriundo do trabalho das marisqueiras, demostrando a dimensão da participação do trabalho feminino para o PIB e o setor da pesca artesanal dessa região do Rio São Francisco. Isso não significa que as marisqueiras não pescam ou coletam outras espécies, mas anuncia a sua decisiva participação na atividade econômica em análise.

Em valores de mercado, os preços das espécies pescadas pelos camponeses pescadores são diferentes, mas apontam para uma possível autonomia dos sujeitos, caso essa modalidade de pesca seja protegida e incentivada. Dessa forma, dos produtos oriundos do estuário do Rio São Francisco e que chegam aos portos das comunidades de 
Brejo Grande, o Robalo é o que apresenta o maior preço, seguido do Guaiamum (Gráfico 06).

Gráfico 06: Preço médio (em reais) das espécies de origem pesca artesanal da Bacia do Rio São Francisco, 2014.

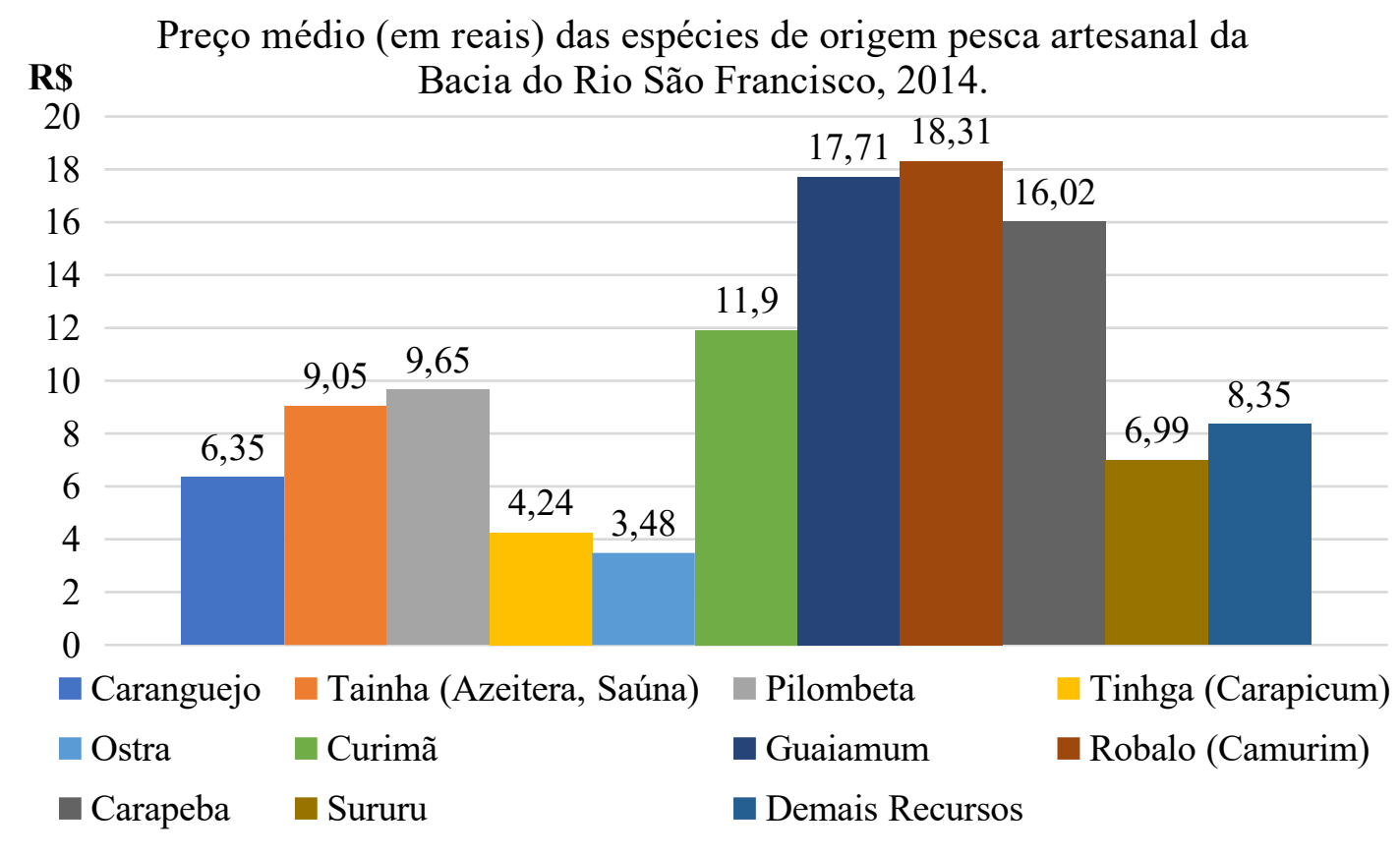

Fonte: Araújo et. al, 2016.

Organização: Jonas Emanuel da Rocha Antão, 2019.

O preço médio de comercialização das espécies nativas oriundas da pesca artesanal registrados por Araújo et. al, (2016), na área estuarina do São Francisco, na região de Brejo Grande, indica que é possível através da preservação do meio ambiente a obtenção de uma renda satisfatória. Para tanto, é necessário a manutenção de um ambiente propício para a realização dessa atividade. No entanto, a proximidade da carcinicultura tende a comprometer a manutenção do ecossistema, com isso, a reprodução das espécies fica impossibilitada, inviabilizando a renda dos pescadores artesanais.

Em 2018, conforme os dados do IBGE, o valor total da produção de camarão foi de R \$ 9.671.000,00 (nove milhões, seiscentos e setenta e um mil reais). Ao dividir o montante arrecado pelo total de camarão produzido, 537.301 quilogramas, cada 
quilograma foi vendido pelo preço médio de R \$17,99 (dezessete reais e noventa e nove centavos).

Desse modo, o preço do camarão é $\mathrm{R} \$ 0,32$ (trinta e dois centavos) mais barato que o preço do Robalo ( $\mathrm{R} \$ 18,31$ ) e $\mathrm{R} \$ 0,28$ (vinte e oito centavos) mais caro que o do Guaiamum (R\$ 17,71) (ARAÚJO et. al., 2016). Esses valores permitem questionar se é coerente destruir o berçário da vida por $\mathrm{R} \$ 17,99$, acarretando um custo ambiental e um prejuízo socioeconômico para a sociedade em geral que futuramente ficará somente com o ônus da carcinicultura.

Segundo a matéria publicada em 28 de Julho de 2019, no site da Assembleia Legislativa do Estado de Sergipe (ASCOM PARLAMENTAR, 2019), existe em Brejo Grande 200 carcinicultores licenciados e 400 em processo de regulamentação, ou seja, o munícipio pode chegar a ter 600 carcinicultores os quais podem ter acesso a um ou mais tanques.

Levando em consideração que existe a possibilidade no aumento de tanques de carcinicultura na região e que segundo os pescadores locais, o quantitativo da coleta e pescaria das espécies nativas na atualidade já é menor que no passado, isso indica que o ônus socioambiental desta atividade já é sentido pelos camponeses pescadores.

Paradoxalmente, com a redução das espécies nativas e a necessidade de garantir o sustento familiar, está ocorrendo uma crescente adesão de muitos camponeses a esse modelo da carcinicultura predatório como forma de garantir o sustento familiar, mesmo que contraditoriamente, o aumento da degradação do mangue ocasione mais danos ambientais na região do rio e estuário.

Esses dados nos levam a questionar para onde estão sendo drenados os recursos e lucros da carcinicultura? E o dinheiro proveniente da venda da pesca artesanal para aonde está indo? Esses valores monetários não alteraram os dados do IDH-M que é de 0,540, considerado baixo "Brejo Grande ocupa a 5325' posição entre os 5.565 municípios brasileiros segundo o IDHM" (BRASIL, 2010).

Além das questões relacionadas aos problemas ambientais originados pela carcinicultura, os camponeses denunciaram que integrante(s) do poder judiciário, carcinicultores e atores do ramo turísticos têm atuado para convencer o poder executivo (presidente da República) e órgãos competentes à liberação de mais empreendimentos nas margens do Rio São Francisco, inclusive em locais demarcados como terra 
quilombolas, aumentando a pressão sobre o ecossistema, o que pode gerar mais conflitos, redução da biodiversidade e aumento da dependência dos camponeses em relação às políticas públicas e uma maior adesão ao ramo da carcinicultura.

\section{Metodologia}

A pesquisa tem como área de estudo município de Brejo Grande no estado do Sergipe. Para tal análise, fez-se necessário o levantamento bibliográfico e a coleta de dados secundários nos órgãos oficiais, Instituto Brasileiro de Geografia e Estatísticas e nos Sites do Ministério da Cidadania e do Atlas da Macro Fauna de Sergipe com objetivo de conhecer a realidade socioambiental e pesqueira do território brejograndense e do estuário do Rio São Francisco.

Neste sentido, utilizou-se das seguintes metodologias e instrumentos de pesquisa: a) a pesquisa de campo para a observação da área, onde foi fotografada; b) as conversas semiestruturadas com os moradores locais; c) as informações coletadas das fontes oficiais e locais junto com os pescadores. Esse conjunto de dados foram tabulados e analisados, permitindo a caracterização da área para entender o contexto socioambiental do município de Brejo Grande, sendo que, essa pesquisa é de natureza quanti-qualitativa.

\section{Considerações finais}

A operacionalização das hidroelétricas, principalmente a de Xingó, entre os municípios de Canindé de São Francisco/SE e Piranhas/AL, interferiu na vazão do Rio São Francisco. Essa interferência foi intensificada após 2003, em razão de um maior controle/redução do volume das águas o que provocou a salinização das águas do rio, inviabilizando a rizicultura, o que possibilitou a ampliação da aquicultura, principalmente a carcinicultura, nas antigas áreas produtoras de arroz.

Assim, os camponeses enfrentam dois conflitos sócioterritoriais, sendo um externo, ocasionado pela hidrelétrica e, outro interno, provocado pela inserção e ampliação da aquicultura, especificamente, a carcinicultura em Brejo Grande. Os dados

e as informações coletadas em campo demonstram que a renda oriunda da 
comercialização do camarão, peixes e mariscos da pesca empresarial, não conseguiram melhorar a qualidade de vida dos camponeses brejo-grandenses.

O aprimoramento da técnica que adentra o território pesqueiro brejo-grandense, que se materializa na engenharia dos tanques, no melhoramento genético das lavas, na ração balanceada do camarão, alterou a vida do coletivo de camponeses, provocando a mortandade das espécies nativas e a destruição do berço marinho (manguezal), tendo em conta, o volume das espécies coletadas e pescadas tem diminuído numa rápida escala temporal. Isso tem reduzido, alterado e afetado o trabalho dos camponeses que necessitam deslocar-se para áreas mais distantes do mangue e do rio para conseguir mariscar e pescar.

Outro fator atual e externo ao ambiente que tem reduzido o valor do pescado comercializado relaciona-se as manchas de petróleo que atingiram o litoral nordestino, inclusive a foz do Rio São Francisco. A dimensão geográfica, econômica e biológica desse impacto ainda não é possível mensurar, mas os pescadores, em audiência pública em 25 de setembro de 2019, relataram que o valor de algumas espécies teve uma redução de $50 \%$ pós-derramamento do petróleo.

Espera-se que este trabalho contribua para as discussões a respeito do tipo de desenvolvimento que é induzido pelo Estado-capital, nas comunidades rurais pescadoras do Brasil. O investimento nesse modelo predatório de carcinicultura, não sinaliza para uma superação das dificuldades socioeconômica da região do Baixo São Francisco, ao contrário, torna-se mais um elemento que tem elevado o custo ambiental, ocasionando impactos negativos à população, contribuindo para a redução da empregabilidade, renda e a biodiversidade e aumentando a possibilidade da desterritorializacão do campesinato brejo-grandense.

\section{AGRADECIMENTOS}

Agradecemos o apoio e auxílio dos camponeses na construção desse trabalho.

Agradecemos também ao apoio da Coordenação de Aperfeiçoamento de Pessoal de Nível Superior (CAPES) 


\section{Nota de rodapé}

${ }^{1}$ Souza (2016), Sócio-espacial com hífen busca aqui evidenciar a análise para além da materialidade, mas também, as relações sociais e as ideias que organizam o Espaço Geográfico.

${ }^{2}$ Entende-se nesse trabalho os camponeses da água como coletivo de sujeitos sociais que apresentam lutas, trabalhos, modo de ser e fazer e espiritualidade que estão integrados ao movimento das águas dos rios, oceanos, lagos, lagoas e dos mares.

${ }^{3}$ Palavra mencionada por Jurandy Marques no Livro a Ecologia do Espírito, alertando para as falaciosas relações ecológicas criadas no/pelo capitalismo (2016, p. 28).

4 Os municípios pesquisados são: Aracaju, Barra dos Coqueiros, Brejo Grande, Estância, Itaporanga D’Ajuda, Indiaroba, Santa Luzia do Itanhi, Pacatuba.

\section{REFERÊNCIAS}

ACOSTA A. O Bem Viver: uma oportunidade para imaginar outros mundos. Tradução de Tadeu Breda. São Paulo: Autonomia Literária/Elefante, 2016. 264 p.

https://doi.org/10.7476/9788578794880.0006

ALVES, M. N. de S. et. al. Dinâmica Geoambiental, processos morfodinâmicos e uso das terras em Brejo Grande, Baixo São Francisco - Sergipe. Revista Brasileira de Geomorfologia, v.8, n.2, p.11-21, 2007, p. 11 a 21.

https://doi.org/10.20502/rbg.v8i2.90

ALVES, M. N. de S. et. al. Mudanças no cotidiano das comunidades tradicionais pesqueiras de Brejo Grande - Sergipe, Brasil. São Cristóvão: Revista GeoNordeste, Ano XXVIII, n. 1, 2017, p. 187-202.

\section{ARAÚJO, A. R. R et. al. Boletim Estatístico da Pesca nos Litorais de Sergipe e}

Extremo Norte da Bahia, 2014. São Cristóvão: Editora UFS, 2016.

ASCOM PALARMENTAR. Em Brejo Grande, deputado Zezinho Sobral defende a carcinicultura sergipana. Assembleia Legislativa do Estado de Sergipe, 2019.

Disponível em: https://al.se.leg.br/em-brejo-grande-deputado-zezinho-sobral-defende-acarcinicultura-sergipana/. Acesso em: 16.12.2018.

ATLASBRASIL. Atlas do Desenvolvimento, 2013. Disponível em:

http://atlasbrasil.org.br. Acesso em: 02.10.2018.

BOFF, L. A Grande Transformação: na economia, na política e na ecologia. Petrópolis/RJ: Vozes, 2014.

BOFF, L. Ética da Vida: A nova centralidade. Rio de Janeiro: Record, 2009. 
BRASIL. Relatório Municipal de Informações de Segurança Alimentar e Nutricional SAN nos Municípios. Brasília: Ministério do Desenvolvimento Social, 2018. Disponível em: https://aplicacoes.mds.gov.br/sagi/FerramentasSAGI/grupo.php?id grupo=209. Acesso em 15.12.2018.

CHESF. Descrição do Aproveitamento de Xingó. Companhia hidrelétrica do São Francisco, c2016. Disponível em:

https://www.chesf.gov.br/SistemaChesf/Pages/SistemaGeracao/Xingo.aspx. Acesso em: 15.12.2018

GALEANO, E. H. As veias abertas da América Latina. Porto Alegre: L\&PM, 2016, p.400.

SANTOS, B. de S. A crítica da razão indolente: Contra o desperdício da experiência. Portugal: Afrontamento, 2000. 415 p.

SANTOS, B. de S. Um discurso sobre as ciências. São Paulo: Cortez, 2008.

SANTOS, B. de S. Para uma sociologia das ausências e uma sociologia das emergências. Revista Crítica de Ciências Sociais, 63, 2002, p. 237-280. Disponível $\mathrm{em}$ : https://www.ces.uc.pt/bss/documentos/sociologia_das_ausencias.pdf. Acesso em: 02 jul. 2018. https://doi.org/10.4000/rccs. 1285

SANTOS, N. D. dos. Pelo espaço do homem camponês: estratégias de reprodução social no sertão dos Estados de Sergipe e Alagoas. Tese (Doutorado em Geografia) Universidade Federal de Sergipe, São Cristóvão, 2012. 291 f.

SOUZA, M. L. de. Os conceitos fundamentais da pesquisa sócio-espaciais. $3^{\mathrm{a}}$ ed. Rio de Janeiro: Bertrand Brasil, 2016. 